\title{
Diagnostic and Prognostic DNA-Karyometry for Cancer Diagnostics
}

\author{
Alfred Böcking ${ }^{1, *}$, David Friedrich ${ }^{2}$, Branko Palcic $^{3}$, Dietrich Meyer-Ebrecht ${ }^{4}$ and Jin Chen $^{5}$ \\ ${ }^{1}$ Institute of Cytopathology, University of Düsseldorf, Germany; Consultant at Institute of Pathology, City \\ Hospital Düren, Germany \\ ${ }^{2}$ Definiens AG, Munich, Germany; Institute of Image Analysis and Computer Vision, RWTH Aachen \\ University, Germany \\ ${ }^{3}$ Cancer Imaging Department, BC Cancer Agency, Vancouver, Canada \\ ${ }^{4}$ Institute of Image Analysis and Computer Vision, RWTH Aachen University, Germany \\ ${ }^{5}$ Department of Software Development, Motic, Xiamen, PR, China
}

\begin{abstract}
Diagnostic and prognostic DNA-karyometry represents an automated computerized microscopical procedure, designed to improve cancer diagnostics at three different aspects:

1. Screening for cancer cells, e.g. in body cavity effusions, urines or mucosal smears

2. Specifying the risk of dysplasias or borderline lesions to progress to manifest cancer, e.g. of oral, bronchial or cervical
\end{abstract} mucosa, or the ovary

3. Grading the malignancy of certain tumors, like prostate cancer.

It combines an automated diagnostic classification of Feulgen-stained nuclei with precise nuclear DNA-measurements. DNA-aneuploidy is used as a specific marker of malignancy and its degree for grading.

All types of cytological specimens can be used after (re-)staining specific for DNA according to Feulgen. Histological specimens are subjected to enzymatic cell separation before Feulgen-staining.

A video-slide scanner is used for automated scanning of microscopical slides. Diagnostic nuclear classifiers have tissuespecifically been trained by an expert-cytopathologist (A. B.), based on Random Forest Classifiers, applying 18 different morphometric features. They achieve an overall accuracy of $91.1 \%$ to differentiate 8 differents types of objects/nuclei. Nuclear DNA-measurements of diploid nuclei achieve a CV of $<3 \%$. DNA-stemline-aneuploidy, applied as a $100 \%$ specific marker for malignancy, is detected and quantified, using internationally accepted algorithms (ESACP 19952001). Suspicion of malignancy is raised in the absence of DNA-aneuploidy but presence of $>1 \%$ morphometrically abnormal nuclei.

Time needed for loading, scanning and validation of results per slide is about 10 minutes. Results of digital diagnostic nuclear classification can be verified by a cytopathologist, using image galleries. Likewise automated diagnostic interpretation of nuclear DNA-distributions can be checked on the monitor, before a pathologists validated diagnoses are issued.

Screening-results are presented for body cavity effusions and urines. Evaluations of dysplasias are reported for oral, bronchial and cervical smears. Results of grading malignancy are shown for prostate cancers.

Keywords: DNA-karyometry, DNA-image-cytometry, nuclear classification, automation, DNA-grading, prostate cancer, early diagnosis, effusions, urinary cytology, cervical cytology, bronchial cytology, oral cytology.

\section{INTRODUCTION}

\section{PRINCIPLES OF MORPHOLOGICAL CANCER DIAGNOSTICS}

Currently cancer diagnoses worldwide are definitely established by the subjective interpretation of morphological features on stained cells (cytology, Figure 1a) or on tissue-sections (histology, Figure 2) by

\footnotetext{
*Address correspondence to this author at the Institute of Cytopathology, University of Düsseldorf, Germany; Consultant at Institute of Pathology, City Hospital Düren, Germany; Tel: 00493040755784;

E-mail: alfred.boecking@web.de
}

(cyto-)pathologists [1,2]. They have learned to interpret complex microscopical images of cells and tissues for years in order to identify certain combinations of features as specific for malignancy, to differentiate thousands of different histogenetic types of cancer and grades of their malignancy [3]. While the diagnosis of malignancy can be made on cells only, for histogenetic typing of tumors, tissue sections have to be analyzed [3-5]. The quality of their diagnoses depends on the depth of individual trainig and aquired experience [6]. Due to the subjectivity of this process, interobersever variation of microscopical cancer-diagnoses is an issue [7]. 


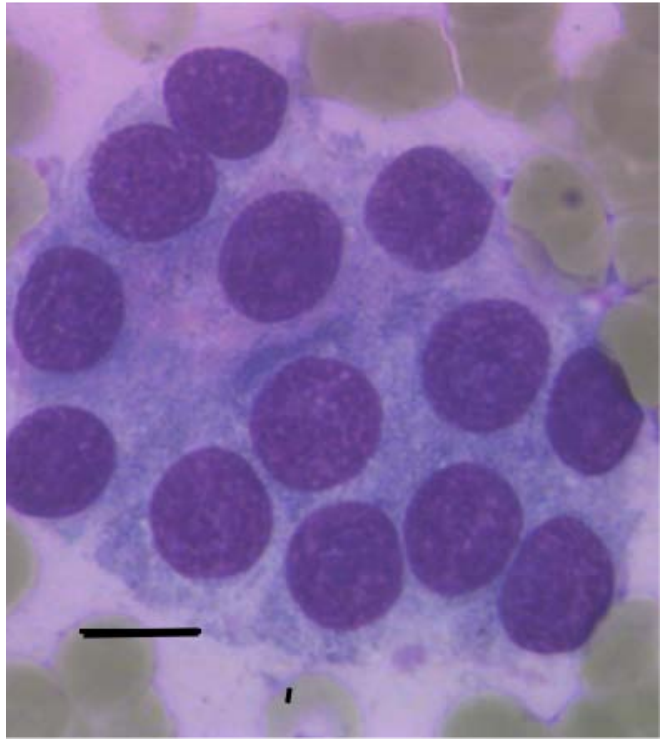

a

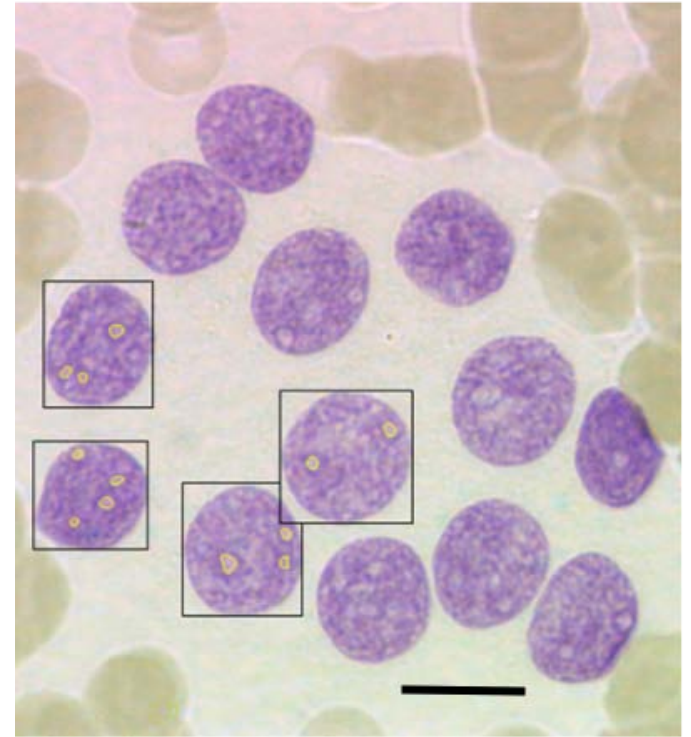

b

Figure 1: MGG- (a) and Feulgen-pararosaniline-stained (b) normal human mesothelial cells. Scale bar: $10 \mu \mathrm{m}$.

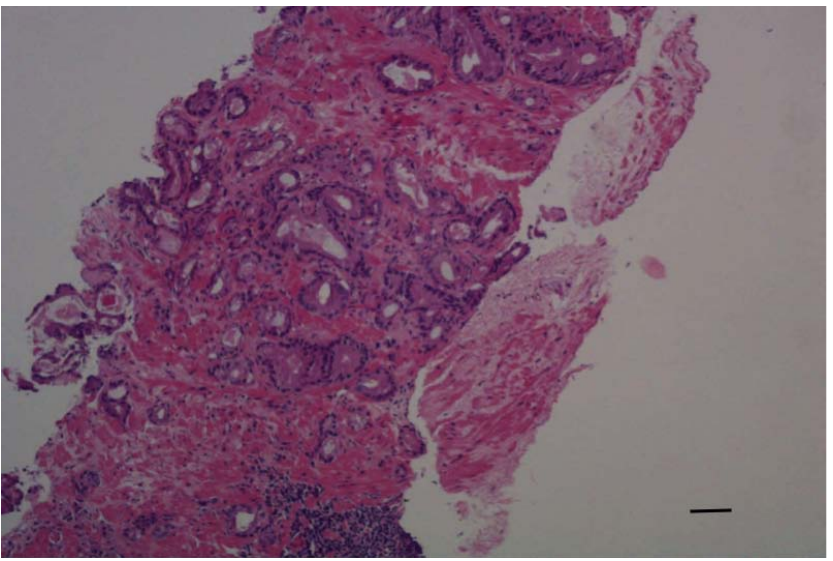

Figure 2: H.E.-stained section of a punch-biopsy from the prostate containing a one millimeter large focus of an adenocarcinoma. Scale bar: $100 \mu \mathrm{m}$.

\section{Dimensions of Microscopical Cancer Diagnoses}

Microscopical cancer diagnoses reveal different dimensions:

Qualitative establishment of malignancy, quantitative grading for the degree of malignancy, histogenetic typing (derivation of an individual cancer from different cell- or tissue types), assessment of tumor spread or progression (staging) and assessment of tumor heterogeneity $[4,8,9]$.

\section{Problems of Microscopical Cancer Diagnostics}

Due to the subjectivity of this traditional procedure, microscopical cancer diagnoses may vary between pathologists, resulting in restricted reproducibility [10]. The quality of diagnoses is dependent on the quality of training, a pathologist has received and the experience he has gained over the years. As the relevant pathogenetic mechanisms that lead to cancer cells take place at the genomic level, morpholgic changes are epiphenomena [11,12], it seems plausible that the earliest evidence of malignany will be observed at the genomic and not at the morphologic level [13]. Similarly, different grades of malignancy are caused by genomic alterations (genetic instability and heterogeneity), resulting secondarily in morphologic changes [13]. Thus, quantifying prognostically valid genomic alterations may allow more reproducible and valid results as compared to subjective microscopical assessment of morphologic aspects [14,15].

\section{Adjuvant Diagnostic Methods}

Supplementing subjective interpretation of cytomorphological or histomorphological features adjuvant methods can help to further specify mircroscopical diagnoses of cancer: Immunocyto- or histochemistry mainly help to specify the histogenetic derivation of tumors by identifying tumortype-specific proteins [16]. Chromosomal Fluorescence In-Situ Hybridisation (FISH) identifies malignancy-associated specific chromosomal aberrations [16]. Argyrophilic Nucleolar Organizer Regions (AgNOr-Analysis) counts Nucleolar Organizer Regions in nuclei as an adjunct in order to assess malignancy. Quantitative Methylation Specific Polymerase Chain Reaction (QMSP) identyfies hypo- or hypermethylation of specific genomic regions as an adjunct to assess malignancy $[18,19]$. DNAcytometry identifies DNA-aneuploidy as a specific 
marker for malignancy and uses its degree for grading $[15,20]$. Genomic-sequencing identifies specific genomic mutations mainly in order to specify susceptibility for certain chemotherapeutic drugs [21].

\section{Diagnostic/Prognostic DNA-Karyometry $[20,22,23]$}

Represents a sequential combination of automated diagnostic classification of nuclei and assessment of
DNA-aneuploidy on morphometrically abnormal ones (Figure 3) using slide scanners (Figure 4) in order to identify cancer cells or to grade their degree of malignancy.

\section{Applications}

Automated screening for cancer cells can be performed on cytological specimens, revealing

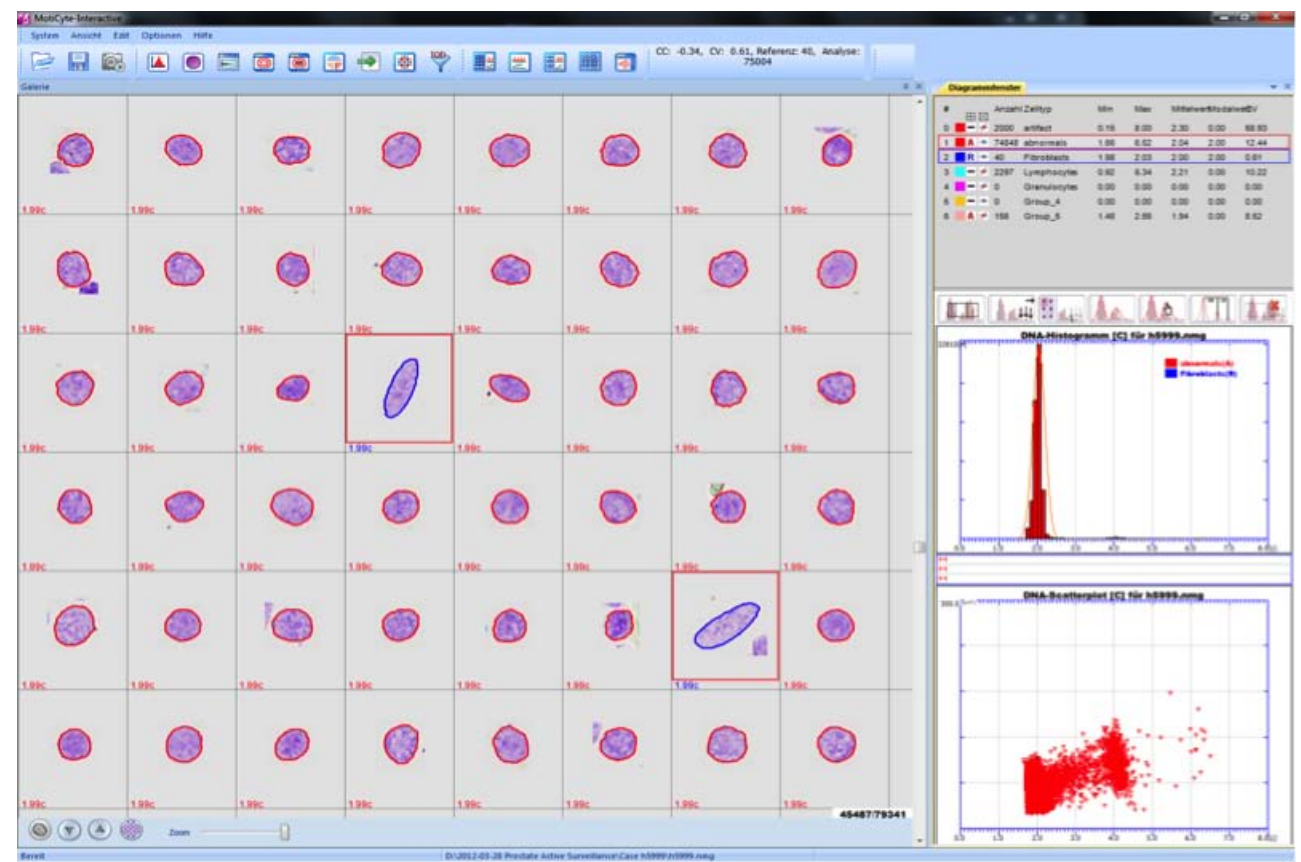

Figure 3: 47 automatically classfied, Feulgen-pararosaniline stained, diploid human prostate cancer cell nuclei and 2 from normal fibroblasts on the monitor of an EasyScan-Al system. DNA-histogram (DNA-content versus frequency) and scatterplot (nuclear DNA-content versus area).

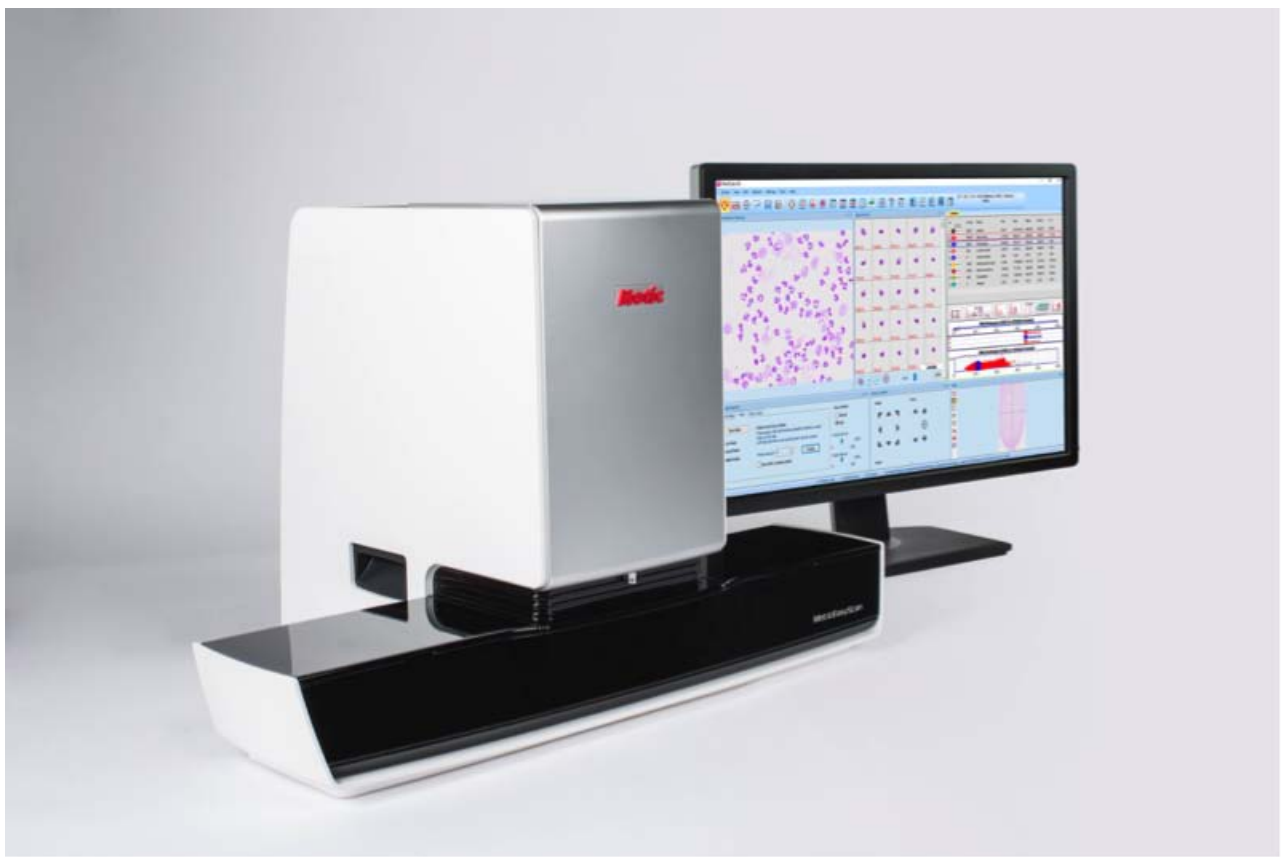

Figure 4: Microscopic digital scanner for automated diagnostic/prognostic DNA-karyometry. 
sufficiently separated cells, like body cavity effusions, urines or liquid-based smear-preparations (oral, cervical) after Feulgen-staining (Figure 1b, protocoll 3).

Specification of the risk of dysplasias or borderline lesions to progress to manifest cancer can be performed on all types of cytological or histological specimens. In the former, regions of interest should be previously marked by felt tip pen on cover glasses before uncovering (protocoll 2), post-fixation with formaldehyde and Feulgen-staining (protocoll 3). Cells must be sufficiently separated. In the latter, diagnostically relevant regions of interest will be marked on stained sections, transferred to paraffinblocks, specifically isolated as decribed below [24] and Feulgen-stained [25].

Grading the malignancy of tumours, like prostate cancers, will be performed on respective, representative tissue sections after enzymatic cell separation according to protocoll 2 and Feulgenstaining, protocoll 3 .

\section{Suitable Specimens (Protocol 1)}

All types of cytological specimens (smears, cytocentrifugations) irrespective their prefixation and staining can be used. Paraffin embedded tissues are subjected to enzymatic cell separation (protocoll 2).

Enzymatic cell separation (protocol 2, suppl. Figures 113)

\section{Feulgen staining (protocol 3, Figures 1b, 5-9)}

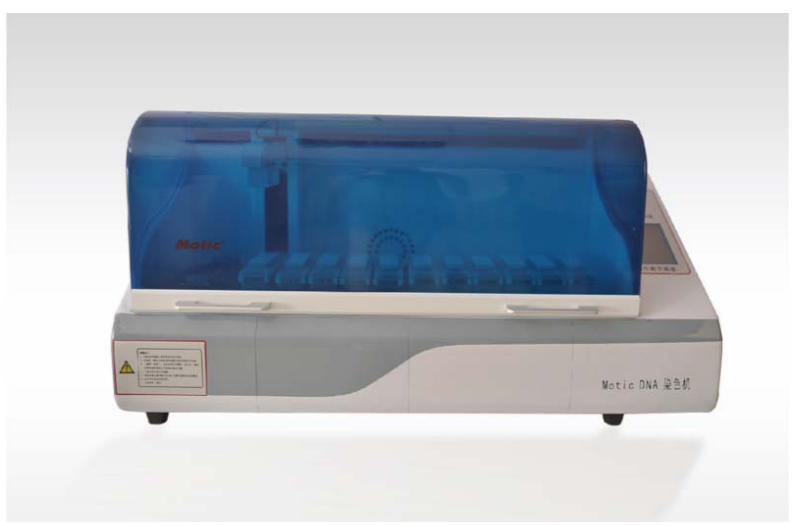

Figure 5: Feulgen-staining machine.

Scanning of slides (protocoll 4, suppl. Figures 14-18)

\section{Supervised Machine Learning for Diagnostic Nuclear Classification}

In order to train digital nuclear classifiers to differentiate ten types of objects, machine learning has

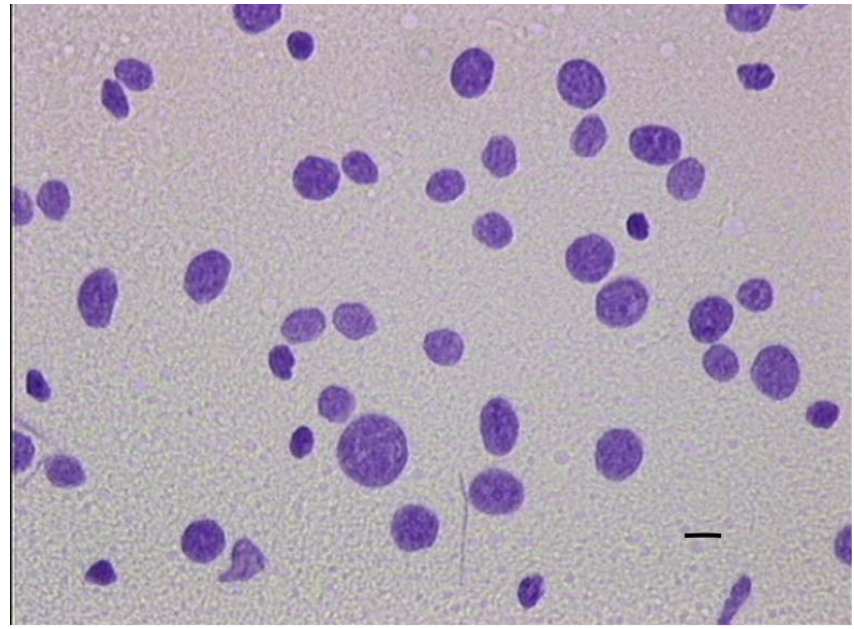

Figure 6: Feulgen-pararosaniline-stained diploid, tetraploid and octoploid rat liver cells. Scale bar: $10 \mu \mathrm{m}$.

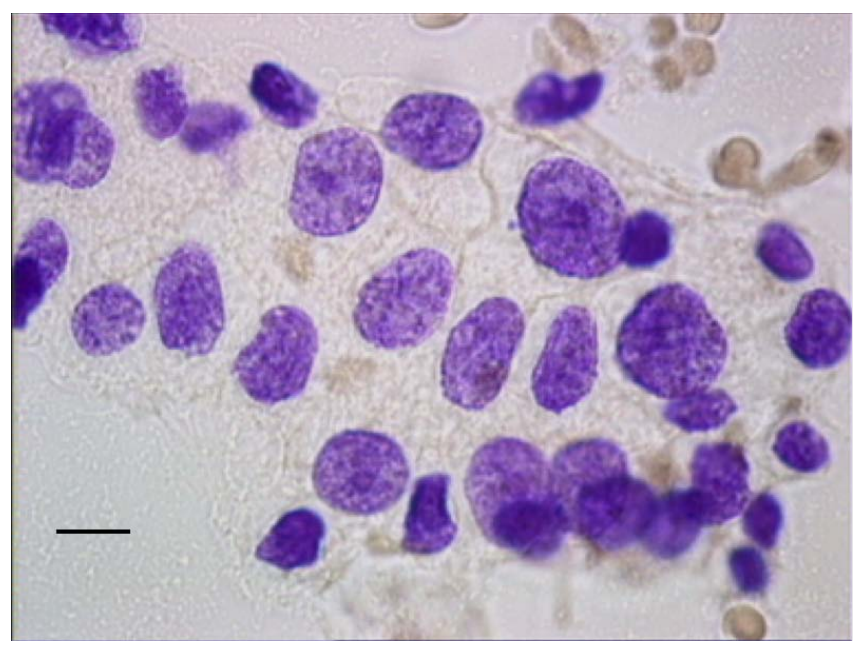

Figure 7: Feulgen-pararosaniline stained, aneuploid human prostatic cancer cell nuclei in a fine-needle-aspiration smear. x 630. Scale bar: $10 \mu \mathrm{m}$.

been performed applying Random Forest Classifier [22]: lymphocytes, granulocytes, macrophages, fibroblasts, nuclei from normal epithelial and mesothelial cells, nuclei from abnormal and atypical epithelial and mesothelial cells, nuclear doublets, defocussed nuclei and artefacts. The categories of abnormal and atypical nuclei are comprised of those from dysplasias (dyskaryoses) and malignant tumors of different origins, respectively. Ten thousands of nuclei from alcohol-fixed cervical smears, air dried body cavity effusion smears and enzymatic cell separation specimens from formalin-fixed prostate cancer tissues were classified by A. B. and a Random Forest Classifier startegy was used. Mean correct classification rate for normal nuclei in effusions was $90.4 \%$ (Figure 8), for abnormal/atypical nuclei $95.2 \%$ (total 54,374; Figure 9). $92.2 \%$ of normal epithelial nuclei have been correctly classified in cervical smears 


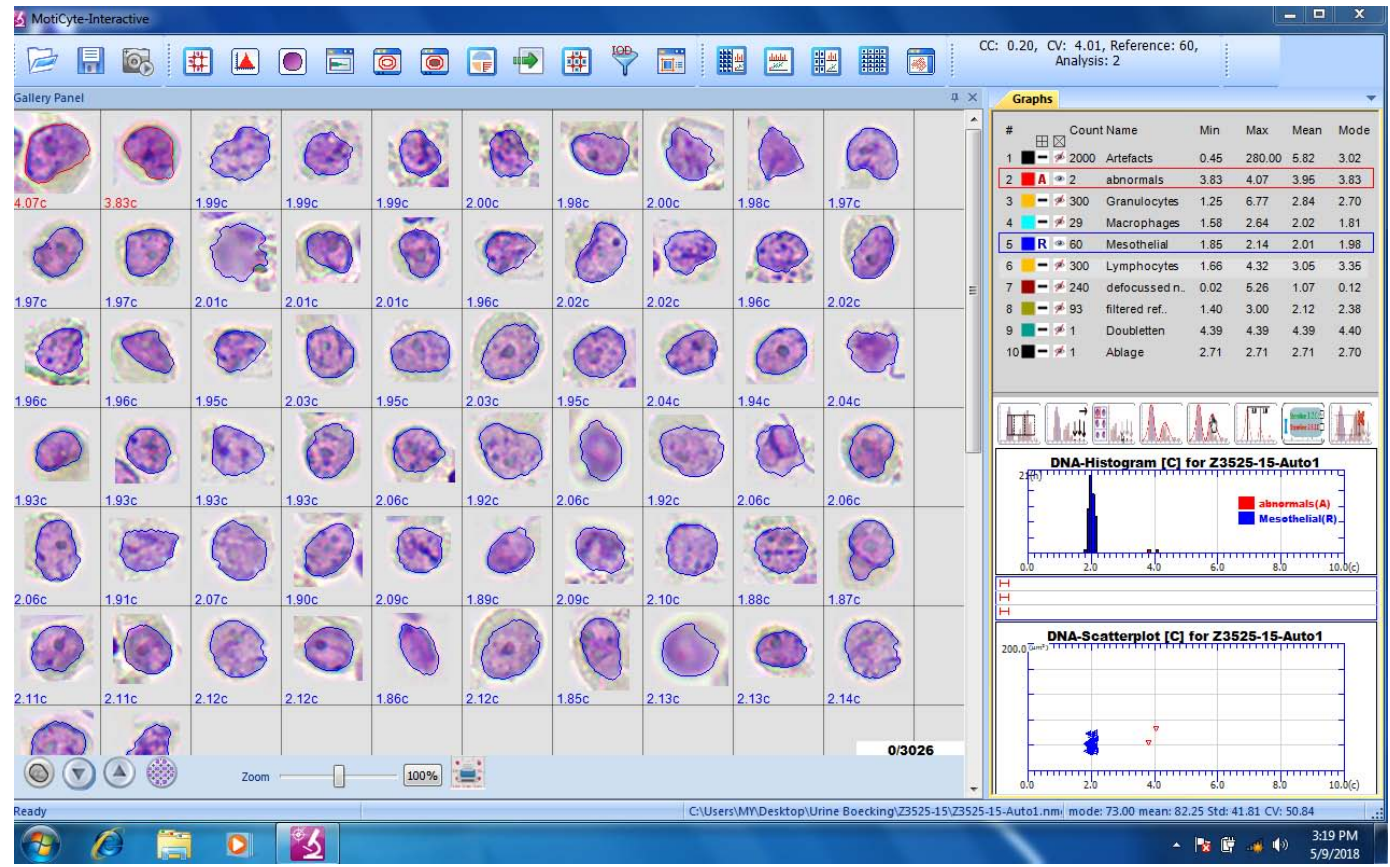

Figure 8: Screenshot showing 60 morphologically normal nuclei from normal mesothelial cells from an effusion (marked blue). Histogram showing normal diploid DNA-distribution.

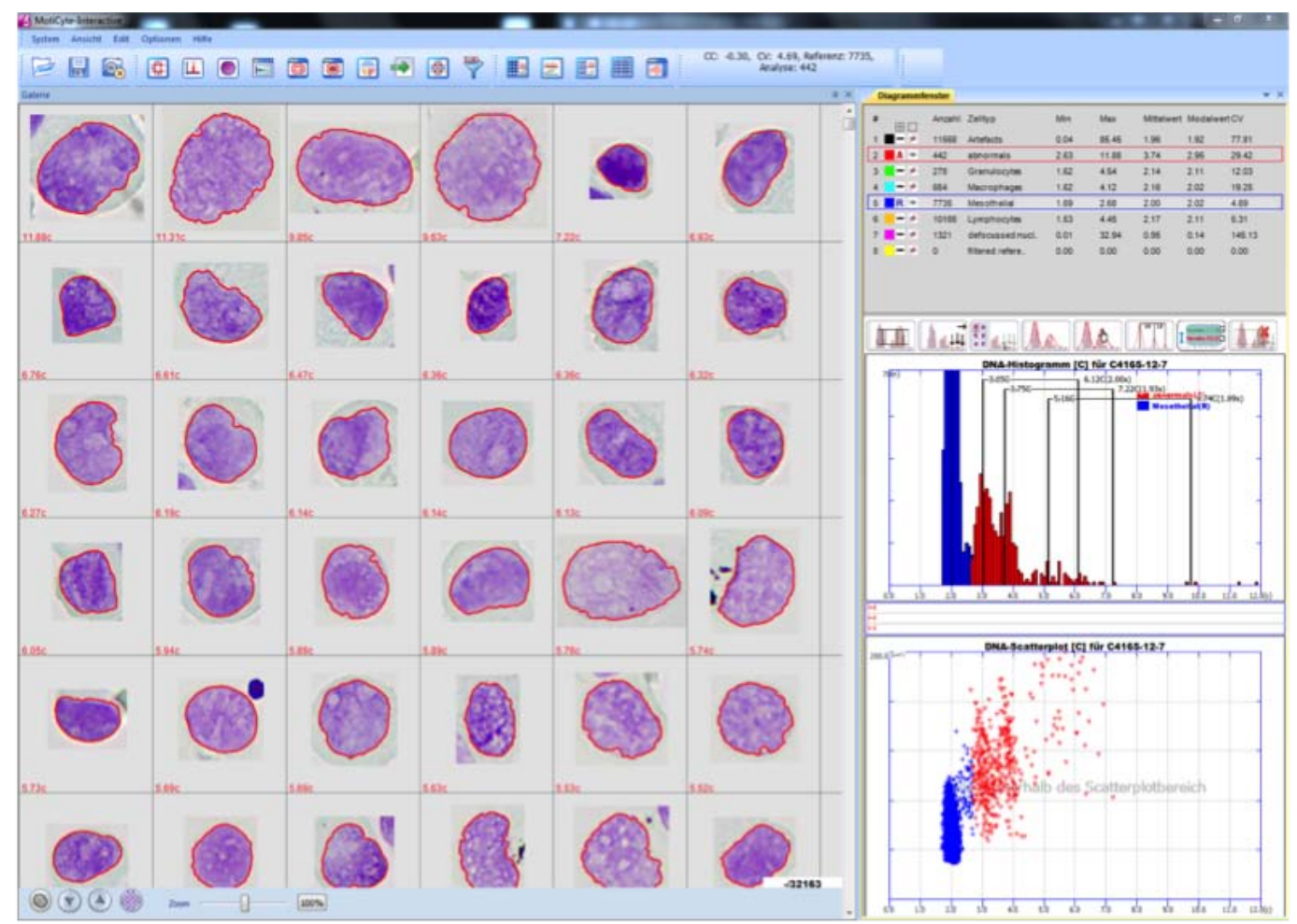

Figure 9: Screenshot showing 36 morphologically abnormal nuclei from a malignant mesothelioma with abnormal DNA-content (marked red): DNA-stemlines at 3.05c, 3.75c and 5.16c, highest nuclear value at 12c.

and $93.8 \%$ of abnormal/atypical nuclei (total 34,676 ). $94.7 \%$ of prostate cancer nuclei have been correcty classified (Figure 3 ) and $94.24 \%$ of artefacts (total $47,982)$. Objects are finally presented separately in respective image galleries for subjective inspection by the user.The percentage of abnormal/atypical nuclei is used to raise a suspicion for cancer cells $(>1 \%)$, not for their definite diagnosis.

\section{Diagnostic Algorithms of DNA-Karyometry [26-29]}

DNA-stemline aneuploidy as a specific marker for malignancy is assumed according to the consensus 
algorithms of the European Society for Analytical Cellular Pathology (ESACP) as defined in [29].

Singlecell-aneuploidy as a marker to suspect malignancy is assumed, if nuclei with a DNA-content $>$ 9c have been detected [29].

Histogram typing for prognostic purposes uses peridiploid, peritetraploid, $x$-ploid and multiploid patterns, as defined by the ESACP [29].

\section{Combined Diagnostic Algorithms}

Malignancy is assumed in the presence of DNAaneuploid stemlines $[29,30]$.

Suspicion of malignancy is assumed if nuclei $>9 \mathrm{c}$ were detected $[29,30]$.

Doubtful, needs further evaluation, is assumed in the absence of DNA-stemline- or -singlecell-aneuploidy but $>1 \%$ morphologically abnormal/atypical nuclei [30].

\section{Final Expert Validation}

After successful scanning of a slide including machine classification of objects, a pathologist should have a final look at the nuclear image gallery in order to exclude artefacts or nuclear doublets (suppl. Figure 19), classified as abnormal/atypical nuclei or missed abnormal abnormal/atypical nuclei under artefacts (Figure 20). Reclassifications can be made by mouseclick. Likewise the machine classification of DNAhistograms, automatically performed by the software (suppl. Figure 21), should be verified by a pathologist before a final diagnosis is issued (suppl. Figures 2227).

\section{Economic Aspects}

Subjective cytologic cancer diagnostics is time consuming. Screening two slides (smears, cytocentrifugations) for the presence of cancer cells needs 5 - 10 minutes, depending on the cell load. Diagnostic accuracy depends on the amount of cells screened, the education and experience of the screener, the time invested for screening and the attention paid. Worldwide there are neither enough specifically educated pathologists nor cytotechnicians. In Germany, recently specialized schools for cytotechnicians have been closed. In many countries of the world no cytotechnicians are available at all.

Thus the benefits of diagnostic cytology (non invasive aquisition of cells, suitable for screening and early diagnosis) do not reach patients sufficiently. Therefore a semi-nautomated approach for the detection and grading the malignancy of cancer cells, the individual diagnostic results of which can be validated by pathologists or cytotechnicians, are desirable and economically advantageous.

\section{PROTOCOLS}

\section{Types of specimens, fixation, prestaining}

1.1. Cytological slides, irrespective of prefixation (air dried; Figures 1, 6), alcohol (Figure 7) or formaline (Figure 2) or prestaining (unstained: Figure 6), MGGstained: Figure 1), Papanicolou (Figure 7) or hematoxiline-eosine (Figure 2) are suitable. $\mathrm{HCl}$ of Feulgen-staining (protocoll 3) will totally remove previous stains.

1.2. All types of formalin-fixed, paraffin-embeded tissues can be subjected to targeted enzymatic cell separation (see protocoll 2). Sufficient primary fixation is necessary. [24]

2. Enzymatic cell separation of histologic specimens

2.1. Define diagnostically resp. prognostically histologically relevant regions of interest (Rol) with felttip-pen on covered slides of stained sections (suppl. Figure 1).

2.2. Transfer their outline on the surface of the respective paraffin-block, containing formalin-fixed tissue, supercially cutting with a pointed scalpel (suppl. Figure 2, 3).

2.3 Cut $2-360 \mu m$ sections on a microtome, select and preserve the Rols (suppl. Figure 4).

2.3. Cut $2-360 \mu m$ sections from formalin-fixed, paraffin embedded transurethral resection specimens from benign prostatic hyperplasia BPH), containing mainly firbromuscular stroma (for obtaining fibroblast nuclei for internal calibration).

2.4. Prepare nylon-gauze-bags from $3 \times 5 \mathrm{~cm}$ by welding its lateral edges using a lighter (suppl. Figures $5,6)$. Mesh width of nylon-gauze should be $50 \mu \mathrm{m}$ (suppl. Figure 5).

2.5. Fill in the sections of Rols and BPH and weld the opening using a lighter (suppl. Figures 6, 7).

2.6. Check perfect closure of the bag. 
2.7. Insert bags in centrifugation $50 \mathrm{ml}$ centrifugation tubes in xylene (supp. Figures 8, 9) and shake over night for deparaffination.

2.8. Rehydrate in each $400 \mathrm{ml}$ of $100 \%, 96 \%$ and $70 \%$ ethanol, aqua dest. and aqua dest. each for 30 $\min$.

2.9. Prepare $0.07 \mathrm{~mol} \mathrm{HCl}$ : add aqua dest. to $7 \mathrm{ml} 1$ $\mathrm{N} \mathrm{HCl}$ up to $100 \mathrm{ml}$.

2.10. Prepare pepsine-solution per capsule: $0.025 \mathrm{~g}$ pepsine-porcine plus $5 \mathrm{ml} 0.07 \mathrm{~mol} \mathrm{HCl}$.

2.11. Prepare PBS-buffer: Mix PBS concentrate 1:10 with aqua dest. Keep in the fridge.

2.12. Transfer gaze-bags filled with deparaffinized sections to $50 \mathrm{ml}$ centrifugation tubes and fill up with $5 \mathrm{ml}$ pepsine-solution at $37^{\circ} \mathrm{C}$.

2.13. Keep for 40 minutes at $37.0^{\circ} \mathrm{C}$ in a water bath and shake strongly every 5 minutes.

2.14. Add $5 \mathrm{ml}$ cold PBS-buffer to stop enzymatic reaction.

2.15. Vortex shortly.

2.16. Spin vessels for 10 minutes at $400 \mathrm{~g}$. Nuclei are now contained in the sediment.

2.17. Remove supernatant up to $1 \mathrm{ml}$, conserve gaze-pouch within supernatant.

2.18. Vortex sediment in residual $1 \mathrm{ml}$ of liquid.

2.19. Centrifugate nuclei on poly-L-lysine coated glass slides for 10 minutes at 12.000 rpm (suppl. Figures 10-12).

2.20. Let slides air-dry over night.

2.21. Cover slides conventional with cover glasses.

3. Feulgen-staining [24].

3.1. With pararosaniline.

3.1.1. A commercially available staining kit for pararosaniline is available.

3.1.2. To prepare $1500 \mathrm{ml}$ sodiumdisulfit-solution for stopping staining, mix $75 \mathrm{ml} 10 \%$ sodiumdisulfit-stocksolution with $1.350 \mathrm{ml}$ aqua dest. and $75 \mathrm{ml} 1 \mathrm{~N} \mathrm{HCl}$. To prepare stock solution, dissolve $100 \mathrm{~g}$ sodimdisultit in $900 \mathrm{ml}$ aqua dest.

3.1.3. See Table 1 for sequential steps of staining air-dried, unfixed slides according to Feulgen.
Table 1: Sequence of Immersions of Air Dried, Unfixed Cytological Slides for Feulgen-Staining with Pararosaniline

\begin{tabular}{|c|c|}
\hline 30 min. & $4 \%$ formalin \\
\hline $10 \mathrm{~min}$. & wash in flowing water \\
\hline $50 \mathrm{~min}$. & $5 \mathrm{~N} \mathrm{HCl}$ at $25,0^{\circ} \mathrm{C}$ \\
\hline $2 \mathrm{~min}$. & Aqua dest. \\
\hline $2 \mathrm{~min}$. & Aqua dest. \\
\hline $60 \mathrm{~min}$. & Schiffs reagent at room temperature \\
\hline $3 \mathrm{~min}$. & Sodiumdisulfite solution \\
\hline $3 \mathrm{~min}$. & Sodiumdidisulfite solution \\
\hline $2 \mathrm{~min}$. & Aqua dest. \\
\hline $2 \mathrm{~min}$. & Aqua dest. \\
\hline $1 \mathrm{~min}$. & $50 \%$ ethanol \\
\hline $1 \mathrm{~min}$. & $70 \%$ ethanol \\
\hline $1 \mathrm{~min}$. & $90 \%$ ethanol \\
\hline $1 \mathrm{~min}$. & $100 \%$ ethanol \\
\hline $1 \mathrm{~min}$. & Xylene \\
\hline
\end{tabular}

3.1.4. Cover slides with cover slips and keep them in the dark to prevent fading of pararosaniline.

3.1.5. See Table 2 for sequential steps of staining previously covered, alcohol fixed and stained slides according to Feulgen.

Table 2: Sequence of Immersions of Previously Covered and Stained Cytological Slides for Feulgen-Staining with Pararosaniline

\begin{tabular}{|c|c|}
\hline Over night & Remove cover glasses in xylene \\
\hline \hline 5 min. & $100 \%$ ethanol \\
\hline 5 min. & $90 \%$ ethanol \\
\hline 5 min. & $70 \%$ ethanol \\
\hline 5 min. & $50 \%$ ethanol \\
\hline 5 min. & Aqua dest. \\
\hline 30 min. & $4 \%$ formalin \\
\hline 10 min. & wash in flowing water \\
\hline 50 min. & $5 \mathrm{~N}$ Cl at $25.0^{\circ} \mathrm{C}$ \\
\hline 2 min. & Aqua dest. \\
\hline 2 min. & Aqua dest. \\
\hline 60 min. & Schiffs reagent at room temperature \\
\hline 3 min. & Sodiumdisulfite solution \\
\hline 3 min. & Sodiumdisulfite solution \\
\hline 2 min. & Aqua dest. \\
\hline 2 min. & Aqua dest. \\
\hline 1 min. & $50 \%$ ethanol \\
\hline 1 min. & $70 \%$ ethanol \\
\hline 1 min. & $90 \%$ ethanol \\
\hline 1 min. & $100 \%$ ethanol \\
\hline 1 min. & Xylene \\
\hline
\end{tabular}


3.1.6. Cover slides with cover slips and store them in the dark to prevent fading of pararosaniline.

\subsection{With thionine}

3.2.1. For Böhm-Sprenger fixative mix $640 \mathrm{ml}$ methanol, $120 \mathrm{ml} 4 \%$ formaldehyde solution and $40 \mathrm{ml}$ acetic acid.

3.2.2. Thionine is commercially available.

3.2.3. For staining solution: $\operatorname{mix} 0.5 \mathrm{~g}$ thionine, 440 $\mathrm{ml}$ aqua dest. and boil for 5 minutes. Cool solution lukewarm. Add $440 \mathrm{ml}$ tertiary butanol, $130 \mathrm{ml} 1 \mathrm{~N} \mathrm{HCl}$ and $8.7 \mathrm{~g}$ sodium bisulfite. Stir for one hour. Leave overnight. Shelf life: two days. Filter. Check pH: $1.4-$ 1.7 .

3.2.4. For rinsing solution: $\operatorname{mix} 15 \mathrm{~g}$ sodium bisufite, $1250 \mathrm{ml}$ aqua dest. and $150 \mathrm{ml} 1 \mathrm{~N} \mathrm{HCl}$. Stir. Shelf life: one week.

3.2.5. See teable 3 for sequential steps to stain airdried, unfixed slides according to Feulgen with thionine.

3.2.6. Cover with cover slips and store slides in the dark (to prevent fading of thionine).

\section{Microscopical Scanning}

The system used for this work has been commercially available. The described protocol can in principle also be used by other scanners provided they have substantially the same key optical variables and metadata, i.e. which have effective pixel sampling density within the slide between $0.1 \mu \mathrm{m}$ and $0.25 \mu \mathrm{m}$ in both the $x$ and $y$ direction, they use optical path with a very high NA between 0.6 and 0.7 at the microscope plane, that the systems' light response is linear within the color range of the stain used, and that they can collect images of every cell nuclei under investigation in a precise focus. As a different slide scanner with similar optical properties could make use of the described protocols, the protocol is generalizable to other scanners; however, in such cases, the different systems would also have to address focusing and segmentation algorithms as well as they would require cytodiagnostic retraining the systems using appropriate nuclear feature sets.

The following parameters should be set before automated scanning of slides:

Registration number of specimen, patients name and birth date, Feulgen-stained used (thionine or pararosaniline), area(s) on slide to be scanned (suppl. Figure 16), tissue type resp.fixation (effusions, air dried; oral/cervical, alcohol-fixed; prostate, formalinefixed (suppl. Figure 17), type of internal reference cells (suppl. Figure 18) and maximum number of nuclei to be stored per type.

\section{Diagnostic/prognostic algorithms}

See diagnostic algorithms above.

\section{Final Review / validation}

See final expert validation above (suppl. Figures 20 24).

\section{REPRESENTATIVE RESULTS}

\section{Screening for Cancer Cells in Effusions [29]}

Serous effusions of body cavities are a frequent clinical event, especially in elder patients. As in about $40 \%$ of these metastasizing malignant tumours or mesotheliomas are the cause, they all have to be microscopically investigated for the presence of cancer cells. Yet, this is time consuming and needs skilled personnel that may not be available everywhere. In an

Table 3: Sequence of Immersions of Air Dried, Unfixed Cytological Slides for Feulgen Staining with Thionine

\begin{tabular}{|c|c|}
\hline 20 min. & 100 ethanol \\
\hline 45 min. & Böhm-Sprenger Fixative \\
\hline 1 min. & Aqua dest. \\
\hline 60 min. & $5 \mathrm{~N} \mathrm{HCl}$ at $25.0^{\circ} \mathrm{C}$ \\
\hline 1 min. & Aqua dest. \\
\hline 60 min. & Thionin stain \\
\hline 1 min. & Aqua dest. \\
\hline 1 min. & Aqua dest. \\
\hline 1 min. & Aqua dest. \\
\hline 15 dips & Rinsing solution \\
\hline 15 dips & Rinsing solution \\
\hline 5 minutes & Rinsing solution \\
\hline 1 min. & Aqua dest. \\
\hline 1 min. & Aqua dest. \\
\hline 1 min. & Aqua dest. \\
\hline 20 dips & $100 \%$ ethanol \\
\hline 20 dips & $100 \%$ ethanol \\
\hline 20 dips & $100 \%$ ethanol \\
\hline 1 min. & Xylene \\
\hline
\end{tabular}


Table 4: Diagnostic accuracy of conventional cytology, manual DNA-Image Cytometry (DNA-ICM), automated DNAKaryometry (DNA-KM), and automated Morphometric Karyometry (M-KM) for the detection of cancer cells in 121 effusion specimens. From Böcking et al., 2019

\begin{tabular}{|c|c|c|c|c|}
\hline & Cytology & Manual DNA-ICM & Automated DNA-KM & Automated M-KM \\
\hline \hline Sensitivity & $88,5 \%$ & $68,5 \%$ & $76,4 \%$ & $100 \%$ \\
\hline Specificity & $100 \%$ & $100 \%$ & $100 \%$ & $70 \%$ \\
\hline PPV & 100 & 100 & 100 & $75 \%$ \\
\hline NPV & $89,4 \%$ & $79,8 \%$ & $83,5 \%$ & $100 \%$ \\
\hline
\end{tabular}

Oxford Level of Evidence Illa study we have investigated 121 smears from body cavity effusions, 62 without and 59 with tumor cells of different origins with automated diagnostic DNA-karyometry. Cytological diagnoses of two experts, immunocytochemistry and clinical follow-up served as gold standard. While mean sensitivity of conventional cytologic inspection of effusions is about $58 \%$ [31], we reached $65.5 \%$ with manual DNA-cytometry and $76.5 \%$ with automated DNA-karyometry at a specificity of $100 \%$ (Table 4 ).

\section{Screening for Cancer Cells in Voided Urines [32]}

Urinary cytology is an appropriate, well established method to identify desquamated urothelial cancer cells from cancers of the urinary bladder, urethers and renal pelvis. It also needs skilled personnel (cytotechnicians) that are not available everywhere. Yet, its mean sensitivity is only about $60 \%$ and specificity $95 \%$. In an Oxford Level of Evidence Illa study we have investigated by manual DNA-image-cytometry 40 urines with and 40 without cancer cells. Clinical followup- and histological diagnoses served as gold stadard. While conventional cytology reached a sensitivity of only $47.5 \%$, DNA-cytometry reached $75.0 \%$ at specificities each of $100 \%$ (Table 5).

Table 5: Diagnostic accuracy of conventional cytology and DNA-Image Cytometry (DNA-ICM) in 80 urinary specimens (from 27 patients with grade 1 , 10 with grade 2,3 with grade 3 urinary bladder cancer and $\mathbf{4 0}$ without). From Planz et al., 2000

\begin{tabular}{|c|c|c|}
\hline & Cytology & DNA-ICM \\
\hline \hline Sensitivity & $47,5 \%$ & $62,5 \%$ \\
\hline Secificity & $100 \%$ & $100 \%$ \\
\hline
\end{tabular}

\section{Screening for Cancer Cells in Oral Smears [33]}

Oral leukopakias mostly are clinical precursors of oral cancers. In order to assess the potentially premalignant nature of leukoplakias, surgical biopsies have to be performed. Yet, the compliance of this invasive procedure by patients is low. Thus currently many oral cancers are identified in a later, incurable stage. Screening for oral leukoplakias in high risk groups and taking brush biopsies, followed by cytological investigation would contribute to lowering the mortality from oral cancer. Yet, mostly skilled personnel for cytological screening of smears is missing. We have performed an Oxford Level of Evidence Ilb study on 251 consecutive patients with oral leukoplaia, 192 without and 59 with oral cancer. Manual DNA-Image-Cytometry had been performed. Subjective screening for cancer cells yielded a sensitivity of $94.6 \%$, while manual DNA-cytometry reached $96.4 \%$ at a specificity of $100 \%$ (Table 6 ).

Table 6: Diagnostic accuracy of conventional cytology and DNA-Image-Cytometry (DNA-ICM) in 251 oral brushings with histological follow-up (56 from squamous cell carcinomas, 83 benign leukoplakias, 112 inflammatory/hyperplastic lesions). From Remmerbach et al., 2001

\begin{tabular}{|c|c|c|}
\hline & Cytology & DNA-ICM \\
\hline \hline Sensitivity & $94,6 \%$ & $96,4 \%$ \\
\hline Specificity & $99,5 \%$ & $100 \%$ \\
\hline PPV & $98,1 \%$ & $100 \%$ \\
\hline NPV & $98,5 \%$ & $99,0 \%$ \\
\hline
\end{tabular}

\section{Assessment the Risk of Bronchial Dysplasias [34]}

Bronchial cancer can be identified and typed histologically on bronchoscopic biopsies or cytologically on bronchial brushings or lavages. Screening smears for the presence of cancer cells is time consuming and needs well trained, experienced personnel. Specifically skilled cytotechnicians are rare. (Semi-)automated screening of bronchial smears for the presence of cancer cells would offer non-invasive bronchial brushings more often. In an Oxford Level of Evidence 
Ilb study we have investigated 70 smears from the bronchi, cytologically suspicious for cancer cells. While sensitivity of manual cytology on bronchial brushbioipsies was $62 \%$, manual DNA-Image-Cytometry yielded $83 \%$ to definitely identify cancer cells, at a specificity of $100 \%$ (Table 7 ).

Table 7: Diagnostic accuracy of conventional cytology and DNA-Image Cytometry (DNA-ICM) in 198 bronchial washings or brushings (70 positive-, 70 negative for cancer cells and 70 equivocal). From Schramm et al., 2011

\begin{tabular}{|c|c|c|}
\hline & Cytology & DNA-ICM \\
\hline \hline Sensitivity & $83,7 \%$ & $79,0 \%$ \\
\hline Specificity & $69,8 \%$ & $98,2 \%$ \\
\hline
\end{tabular}

\section{Assessment of Cervical Dysplasias [35]}

Screening women for early cervical cancers, using the cytological investigation of cervical smears according to Papanicolaou is well established and has successfully reduced the lethality of this frequent disease in many countries. Yet, in about 5\% the cytological diagnostic results are neither undoubtedly positive nor negative but suspicious or doubtful. Pathologists call this histologically mild or moderate Cervical Intraepithelial Neoplasia (CIN I or CIN II), or cytologically Low- or High-Grade Intraepithelial Neoplasia (L-SIL, H-SIL), Atypical Squamous Cells (ASC) or Atypical Glandular Cells (AGC). Yet, in an individual case it remains an open question, if a suspicious lesion is prospectively malignant or not. As DNA-aneuploidy represents an internationally accepted marker of (prospective) malignancy [12,15,29], we have investigated in an Oxford Level Ilb study if the cytometric evidence of DNA-aneuploidy in LSIL, ASC and $A G C$ cervical smears is able to predict susequently histologically proven malignancy and thus cervical cancer. In 108 such suspicious cervical smears the positive predictive value of cytology for histologically proven $>=$ CIN II lesions was $35.2 \%$, that of manual DNA-cytometry 65.9\% (Table 8).

6. Grading the Malignancy of Prostate Cancers [36, 37]

The malignant potential of early localized cancers of the prostate is very heterogenous. About $40 \%$ of newly detected cancers are thus principally suitable for the conservative strategy of Active Suveillance (AS) instead of radical prostatectomy or radiation. Yet, based on conventional, subjective histologic grading
Table 8: Diagnostic accuracy of conventional cytology and DNA-Image Cytometry (DNA-ICM) in 196 cytologically suspicious cervical smears (ASC, LSIL, AGC) for the subsequent histological detection of of >= CIN3 lesions. From Grote et al., 2004

\begin{tabular}{|c|c|c|}
\hline & Cytology & DNA-ICM \\
\hline \hline Sensitivity & $100 \%$ & $100 \%$ \\
\hline Specificity & - & $51,4 \%$ \\
\hline PPV & $12,4 \%$ & $43,9 \%$ \\
\hline NPV & - & $93,3 \%$ \\
\hline
\end{tabular}

according to Gleason and clinical stages I or Ila/b, about $30 \%$ of prostate cancers, subjected to AS will nevertheless suffer progress, despite an apparently low Gleason-Score of 6 . It would be helpful to establish an objective, prognostically valid parameter that is able to exclude progression within four years despite renouncing active therapy. We have investigated this for DNA-grading the malignancy of clinically localized prostate cancers in comparison with Gleason score in an Oxford Level $1 \mathrm{~b}$-study on residual tissue in biopsies of 80 patients. While the prediction of non progression for 4.1 years under Active Surveillance for the GleasonScore of a reference pathologist yielded a sensitivity of $79.2 \%$, automated DNA-karyometry reached $100 \%$. Specificities were $23.5 \%$ and $50.8 \%$ (Table 9 ).

Table 9: Diagnostic accuracy of Gleason-scoring by a reference pathologist and of automated prognostic DNA-Karyometry for the prediction of progression within four years in 80 untreated prostate cancer patients under active surveillance. From Böcking et al., 2017

\begin{tabular}{|c|c|c|}
\hline & Reference Pathologist & DNA-Karyometry \\
\hline \hline Sensitivity & $23,5 \%$ & $100 \%$ \\
\hline Specificity & $87,3 \%$ & $50,8 \%$ \\
\hline PPV & $33,3 \%$ & $35,4 \%$ \\
\hline NPV & $80,9 \%$ & $100 \%$ \\
\hline
\end{tabular}

\section{DISCUSSION}

Automated diagnostic respectively prognostic DNAkaryometry represents an innovative, hybride digital microscopic techology that aims at:

a. assisting (cyto-)pathologists in sceening repetitive cytological specimens for the presence of cancer cells (body cavity effusions, urines, oral or cervical smears); 
b. predicting the prospective behaviour of dysplasias and borderline lesions (oral, cervical, gastric, ovarian) as to progess to histologically obvious malignancy;

c. grading the malignancy of certain types of cancers (e.g. of the prostate).

It combines an automated digital morphological classification of nuclei as belonging to different cell types, based on supervised machine learning, with the precise assessment of nuclear DNA-content of morphologically suspicious cells. Tissue-type specific supervised machine learning has been applied for teaching the machine to classify segmented objects into eight different classes of nuclei (lymphocytes, granulocytes, macrophages, fibroblasts, normal and abnormal epithelial and mesothelial cells) and three different classes of artefacts (nuclear doublets, defocussed nuclei, others). Internal calibration of the normal nuclear DNA-content is perfomred after DNAspecific Feulgen-staimg with obviously morphologically normal nuclei (e.g. of lymphocytes or fibroblasts). The distribution of nuclear DNA-values of morphologically abnormal nuclei is analysed concerning the presence or absence of DNA-aneuploidy as a specific marker for malignancy. The degree of DNA-aneuploidy is used for grading the malignancy of prostate cancers. Internationally consented diagnostic and prognostic algorithms of DNA-cytometry are used (Consensus Reports of the European Society for Analytical Cellular Pathology, ESACP [26-29]. A rate of $>1 \%$ of morphologically abnormal nuclei is used as an indicator of suspicion of malignancy in the absence of DNAaneuploidy.

Loading slides and setting the parameters of the device, automated scanning, nuclear classification and DNA-measurements as well as final checkup of nuclear classifications and diagnostic interpretations of DNAdistributions takes about 10 minutes per specimen. Final diagnostic or prognostic results are all validted by a pathologist.

The technology thus helps to imrove diagnstic or prognostic accuracy of microscopical cancer diagnostics and to provide economic screening for cancer cells where cytotechnicians are rare or missing.

\section{DISCLOSURES}

Motic, Xiamen, China has provided half an academic position for two years to sponsor our development.

\section{ACKNOWLEDEMENTS}

We thankfully acknowledge the long lasting, generous support of Prof. Dr. Bernd Klosterhalfen, director of the Institute of Pathology, City Hospital of Düren, Germany in developing, testing and applying the descibed technology. We furthermore thank Mrs. Claudia Banfai for many years of excellent technical support and critical input.

\section{SUPPLEMENTARY FIGURES}

The supplementary figures can be downloaded from the journal website along with the article.

\section{REFERENCES}

[1] Goldblum JR, Lamps LW, McKenney J, Myers JL, Rosai and Ackermann's surgical pathology. 11th ed. The C. V. Mosby Company, St. Louis, Toronto, London 2018.

[2] Koss LG, Melamed M. Koss'diagnostic cytology and its histopathological basis. Lippincott, Williams \& Wilkins, Philadelphia, Toronto 2006

[3] Kayser K, Borkenfeld S, Carvalho R, Dejounis A, Kayser G. How to analyze structure and function in tissue - based diagnosis? Diagnostic Pathology 2016; 4(1): 106-128.

[4] Vuletic F, Zajec V, Vuletic LB, Seiwerth S. Intratumoral heterogeneity. Diagnostic Pathology 2018; 4(1): 257-271.

[5] Kayser K, Borkenfeld S, Kayser G. Digital image content and context information in tissue based diagnosis. Diagnostic Pathology 2018; 4(1): 269-287.

[6] Fritz A, et al. International classification of diseases for oncology. 3rd ed, World Health Organization, Geneva 2000.

[7] Griffith DFR, et al. A study of Gleason score interpretation in different groups of UK pthologiasts: techniques for improving reproducibility. Histopathology 2006; 48: 655-662. https://doi.org/10.1111/j.1365-2559.2006.02394.x

[8] Veloso $\mathrm{S}$, et al. Interobserver agreement of Gleason score and modified Gleason score in needle biopsy and surgical specimen of prostate cancer. Clinical Urology 2007; 33(5): 639-651. https://doi.org/10.1590/S1677-55382007000500005

[9] Cyll K, et al. Tumour heterogeneity poses a significant challenge to cancer biomarker research. British Journal of Cancer 2017; 117: 367-375 https://doi.org/10.1038/bjc.2017.171

[10] Burchard $M$, et al. Interobserver reproducibility of Gleason grading: evaluation using prostate cancer tissue microarrays Journal of Cancer Research and Clinical Oncology 2008; 134: 1071-1078. https://doi.org/10.1007/s00432-008-0388-0

[11] Duesberg $P$, Li R, Fabarius A, Hehlmann R. The chromosomal basis of cancer. Cellular Oncology 2005; 27: 293-318.

[12] Bloomfield M, Duesberg P. Karyotype alteration generates the neoplastic phenotype of SV40-infected human and rodent cells. Molecular Cytogenetics 2015; 8: 79-108. https://doi.org/10.1186/s13039-015-0183-y

[13] Duesberg P, McCormack A. Immortality of cancers. A consequence of inherent karyotypic variations and selection for autonomy. Cell Cycle 2013; 12(5): 783-802. https://doi.org/10.4161/cc.23720

[14] Heng $\mathrm{H}$, et al. Cancer progression by non-clonal chromosome aberrations. Journal of Cellular Biochememistry 2006; 98: 1424-1435.

https://doi.org/10.1002/jcb.20964 
[15] Böcking A. Comparability of tumor-cytogenetics and -DNAcytometry. Molecular Cytogenetics 2015; 8: 28-30. https://doi.org/10.1186/s13039-015-0132-9

[16] Onofre ASC, Pomjanski N, Buckstegge B, Böcking A. Immunocytochemical diagnosis of hepatocellular carcinoma and identification of carcinomas of unknown primary metastatic to the liver on fine-needle aspiration biopsies. Cancer Cytopathology 2007; 111: 259-268. https://doi.org/10.1002/cncr.22768

[17] Bubendorf L, Grote HJ, Syriänen K. Molecular Techniques. In Bibbo M, Wilbur DC, Eds. Comprehensive Cytopathology. Philadelphia: Saunders Elsevier 2008; Vol. 3: pp. 1071-1088. https://doi.org/10.1016/B978-141604208-2.10036-3

[18] Grote HJ, Schmiemann V, Geddert $H$, et al. Detection of RASSF1A aberrant promoter methylation in bronchial aspirates from patients with suspected lung cancer. Cancer Cytopathoogy 2006; 108: 129-134. https://doi.org/10.1002/cncr.21717

[19] Kahn SL, Ronnett BM, Grant PE, Gustafson KS. Quantitative methylation-specific PCR for the detection of aberrant DNAmethylation in liquid Pap-tests. Cancer 2008; 114(1): 57-64. https://doi.org/10.1002/cncr.23258

[20] Böcking A, et al. Diagnostic cytometry, In: Mehrothra R, Ed. Oral cytology. A concise guide. Springer New-York 2013; pp. 125-146.

[21] Gerhauser C, et al. Molecular evolution of early-onset prostate cancer identifies molecular risk markers and clinical trajectories. Cancer Cell 2018; 34(6): 996-1011. https://doi.org/10.1016/j.ccell.2018.10.016

[22] Friedrich D. Effective improvement of cancer diagnostics and prognostics by computer-assisted cell image analysis. PhDthesis. Aachen, Germany. RWTH Aachen University 2015.

[23] Böcking A, Chen J, Friedrich D, Meyer-Ebrecht D. Computerunterstützte Erkennung von Krebszellen mittels DNAKaryometrie. Trillium Krebsmedizin 2015; 24: 208-211.

[24] Hedley DF, Friedlander M, Taylor TW. Application of flow cytometry to paraffin-embedded archival material for the study of aneuploidy and its clinical significance. Cytometry 1985; 6: 327-333.

https://doi.org/10.1002/cyto.990060409

[25] Feulgen R, Rossenbeck H. Mikroskopisch-chemischer Nachweis einer Nukleinsäure vom Typ der Thymonukleinsäure und die darauf beruhende elektive Färbung von Zellkernen in mikroskopischen Präparaten. Hoppe-Seyler's Zeitschrift für Phyiologische Chemie 1924; 135: 203-248. https://doi.org/10.1515/bchm2.1924.135.5-6.203

[26] Böcking A, Giroud F, Reith A. Consensus report of the ESACP task force on standardization of diagnostic DNA image cytometry. Analytical Cellular Pathoogy 1995; 8: 6774.
[27]

Haroske G, Giroud F, Böcking A. DNA image cytometry. Part I. basic considerations and recommendations for preparation, measurement and interpretation. European Society for Analytical Cellular Pathology. Analytical Cellular Pathology 1998; 17: 189-200. https://doi.org/10.1155/1998/390837

[28] Giroud F, Haroske G, Reith A, Böcking A. 1997 ESACP consensus report on diagnostic DNA image cytometry. Part II: specific reccommendations for quality assurance. European Society for Analytical Cellular Pathology. Analytical Cellular Pathology 1998; 17: 201-208. https://doi.org/10.1155/1998/237659

[29] Haroske G, Baak JP, Danielsen H, et al. Fourth updated consensus report on diagnostic DNA image cytometry. Anayticall Cellular Pathology 2001; 23: 89-95. https://doi.org/10.1155/2001/657642

[30] Böcking A, Friedrich D, Meyer-Ebrecht D, Zhu C. Feider A, Biesterfeld S. Automated detection of cancer cells in efusion specimens by DNA karyometry. Cancer Cytopathology 2019; 127: $18-25$.

https://doi.org/10.1002/cncy.22072

[31] Bedrossian CWM. Malignant effusions. A multimodal approach to cytological diagnosis. Igaku-Shoin Medical Publishers, New York 1994.

[32] Planz B, Synek C, Robben J, Böcking A, Marberger M. Diagnostic accuracy of DNA image cytometry with cells from voided urine in the detection of bladder cancer. Urology 56: 2000; $782-786$. https://doi.org/10.1016/S0090-4295(00)00765-2

[33] Remmerbach $T$, Weidenbach $H$, Pomjanski $N$, Knops $C$, Mathes S, Hemprich A, Böcking A. Cytologic and DNAcytometric diagnosis of oral cancer. Analytical Cellular Pathology 2001; 22: 211-221. https://doi.org/10.1155/2001/807358

[34] Schramm M, Wrobel C, Born I, Kazimirek M, Pomjanski N, William M, Kappes R, Gerharz CD, Biesterfeld S, Böcking A. Equivocal cytology in lung cancer diagnosis. Improvement of diagnostic accuracy using adjuvant multicolor FISH, DNAimage cytometry, and quantitative promoter hypermethylation analysis. Cancer Cytopathoogy 2011; 119: 177-192. https://doi.org/10.1002/cncy.20142

[35] Grote HJ, Huy VQN, Leick AG, Böcking A. Identification of progressive cervical epithelial cell abnormalities using DNA image cytometry. Cancer Cytopathology 2004; 102: 373-379. https://doi.org/10.1002/cncr.20644

[36] Böcking A. Prediction of non-progression in prostate cancer patients under active surveillancy by DNA-karyometry. SM Journal of Urology 2017; 3(1): 1030-1036. https://doi.org/10.36876/smju.1030

[37] Böcking A, Tils M, Schramm M, Tils M, Biesterfeld S. DNAcytometric grading of prostate cancer. Systematic review of the literature. Pathol Discovery 2014; 2: 1-20. https://doi.org/10.7243/2052-7896-2-7

\section{DOI: https://doi.org/10.30683/1929-2279.2020.09.05}

(C) 2020 Böcking et al.; Licensee Neoplasia Research.

This is an open access article licensed under the terms of the Creative Commons Attribution Non-Commercial License (http://creativecommons.org/licenses/by-nc/3.0/) which permits unrestricted, non-commercial use, distribution and reproduction in any medium, provided the work is properly cited. 